\title{
Distribution and current infection status of Biomphalaria straminea in Hong Kong
}

Xin Zeng ${ }^{1,2,3}$, Wing Chung Yiu' ${ }^{1}$, Kwan Ho Cheung ${ }^{1}$, Ho Yin Yip ${ }^{1}$, Wenyan Nong ${ }^{1}$, Ping He ${ }^{2,3}$, Dongjuan Yuan ${ }^{2,3}$, David Rollinson ${ }^{4}$, Jian-Wen Qiu ${ }^{5}$, Ming Chiu Fung ${ }^{1,3}$, Zhongdao Wu ${ }^{2,3^{*}}$ and Jerome Ho Lam Hui ${ }^{*^{*}}$

\begin{abstract}
Background: Schistosomiasis, also generally known as snail fever, is a parasitic disease caused by trematode flatworms of the genus Schistosoma. In Hong Kong and mainland China, the freshwater snail Biomphalaria straminea has been introduced and has the potential to transmit intestinal schistosomiasis caused by $S$. mansoni, a parasite of man which has a wide distribution in Africa and parts of the New World, especially Brazil. The first identification of B. straminea in Hong Kong dates back to the 1970s, and its geographical distribution, phylogenetic relationships, and infection status have not been updated for more than 30 years. Thus, this study aims to reveal the distribution and current infection status of $B$. straminea in contemporary Hong Kong.

Methods: Snails were collected from different parts of Hong Kong from July 2016 to January 2017. Both anatomical and molecular methods were applied to identify B. straminea. Cytochrome c oxidase subunit 1 (cox1), internal transcribed spacer 1 (ITS1), 5.8S rDNA, internal transcribed spacer 2 (ITS2), and 16S ribosomal DNA (rDNA) were sequenced from individual snails and analyzed. To detect the presence of $S$. mansoni, both biopsy and PCR analyses were carried out.
\end{abstract}

Results: Using both anatomical and molecular analyses, this study demonstrated the existence of black- and red-coloured shell B. straminea in different districts in the New Territories in Hong Kong, including places close to the mainland China border. None of the B. straminea $(n=87)$ investigated were found to be infected with $S$. mansoni when tested by biopsy and PCR. The Hong Kong B. straminea are genetically indistinguishable, based on the chosen molecular markers (COX1, ITS1-5.8S-ITS2, and 16S rDNA), and are similar to those obtained in mainland China and South America.

Conclusion: Biomphalaria straminea is now well established in freshwater habitats in Hong Kong. No evidence of infection with S. mansoni has been found. Surveillance should be continued to monitor and better understand this schistosomiasis intermediate host in mainland China and Hong Kong.

Keywords: Schistosomiasis, Schistosoma mansoni, Biomphalaria straminea, Hong Kong, China

\section{Background}

With an estimate of almost 240 million people infected worldwide, schistosomiasis is considered by the World Health Organization as the second most prevalent parasitic disease after malaria. This disease remains a global

\footnotetext{
* Correspondence: wuzhd@mail.sysu.edu.cn; jeromehui@cuhk.edu.hk ${ }^{2}$ Department of Parasitology, Zhongshan School of Medicine, Sun Yat-sen University, Guangzhou, Guangdong Province, People's Republic of China ${ }^{1}$ School of Life Science, State Key Laboratory of Agrobiotechnology, The Chinese University of Hong Kong, Hong Kong Special Administrative Region, People's Republic of China

Full list of author information is available at the end of the article
}

health problem resulting in economic and social burdens [1]. One of the most widespread of the human-infecting species is Schistosoma mansoni, which is estimated to infect more than 80 million people globally. Intestinal schistosomiasis caused by $S$. mansoni occurs in Africa, Madagascar, the Middle East, the Caribbean, Brazil, Venezuela and Suriname.

Infections with $S$. mansoni in humans are initiated by the release of cercariae by various species of freshwater snails of the genus Biomphalaria; cercariae penetrate the skin of people when exposed in water. Given the parasite 
life-cycle and a combination of other factors, including poor public health education, water quality, sanitation and natural disasters (such as flooding that may spread the snails), the number of people infected with S. mansoni is especially high in socioeconomic underdeveloped countries [1]. Intestinal schistosomiasis caused by $S$. mansoni is not currently endemic in Hong Kong and mainland China, while another species Schistosoma japonicum transmitted by the prosobranch snails Oncomelania spp., has been the subject of intense control measures in China. According to the Law of Communicable Diseases Prevention and Control in China, schistosomiasis is currently listed in the category $\mathrm{B}$ of notifiable diseases to be reported. In 2011, there were a total of 4483 cases of schistosomiasis caused by Schistosoma japonicum reported to the Ministry of Health nationwide in China. Recently, imported cases of schistosomiasis caused by Schistosoma mansoni have been reported to be increasing in China [2].
To date, there are 34 described species of Biomphalaria snails, 18 of which have been demonstrated to be infected by $S$. mansoni, either naturally or experimentally [3]. Different geographical locations are dominated by different species of Biomphalaria, for instance, $B$. pfeifferi, $B$. alexandrina and $B$. sudanica serve as the main intermediate hosts of $S$. mansoni in Africa, Madagascar and the Middle East, while B. glabrata dominates in the Neotropics. In some areas, other species of Biomphalaria such as B. straminea, B. tenagophila, $B$. choanomphala, B. camerunensis and B. stanleyi, have been shown to play important roles in transmitting schistosomiasis [3-6]. Transmission of imported schistosomiasis will not occur in places without the host snails $[7,8]$, and hence, understanding the biology and distribution of the intermediate hosts contributes to the prevention and control of schistosomiasis.

Globalization and traveling are two important factors that aid the spread of schistosomiasis. For example,

Table 1 Field sampling sites for snails Biomphalaria straminea in Hong Kong

\begin{tabular}{|c|c|c|c|}
\hline Sampling site & District & GPS coordinates & B. straminea \\
\hline Lo Wu Border (LW) & New Territories & $22.526486,114.112326$ & Yes \\
\hline Ping Che Road (PCL) & New Territories & $22.516650,114.166232$ & Yes \\
\hline Shek Sheung River(SSH) & New Territories & $22.505979,114.118531$ & Yes \\
\hline Ng Tung River (NgT) & New Territories & $22.507454,114.135875$ & Yes \\
\hline Shan Pui River 1 (SB) & New Territories & $22.455540,114.031890$ & Yes \\
\hline Kam Po Road (JP) & New Territories & $22.433702,114.067210$ & Yes \\
\hline Fu Hang Road (HKL) & New Territories & $22.414986,113.984772$ & Yes \\
\hline Sam Long Apartments (SG) & New Territories & $22.333522,114.239565$ & Yes \\
\hline Little Hawaii Trail & New Territories & $22.331859,114.247215$ & No \\
\hline Ta Shek Wu & New Territories & $22.462304,114.106114$ & No \\
\hline Tan Chuk Hang & New Territories & $22.512544,114.177685$ & No \\
\hline Chinese University of Hong Kong & New Territories & $22.416144,114.207924$ & No \\
\hline Upper Shing Mun Reservoir & New Territories & $22.392784,114.149916$ & No \\
\hline Kowloon Reservoir & New Territories & $22.351072,114.153883$ & No \\
\hline Ho Chung & New Territories & $22.354735,114.246225$ & No \\
\hline Lam Uk Tsuen & New Territories & $22.451903,114.027649$ & No \\
\hline Fairview Park & New Territories & $22.472910,114.050549$ & No \\
\hline Shan Pui River 2 & New Territories & $22.469330,114.030305$ & No \\
\hline Lee Uk Tsuen & New Territories & $22.537282,114.150019$ & No \\
\hline Tung Chung River & Lantau Island & $22.276882,113.931202$ & No \\
\hline Wong Lung Hang Road & Lantau Island & $22.279049,113.941154$ & No \\
\hline Hong Kong University & Hong Kong Island & $22.282796,114.138440$ & No \\
\hline Hong Kong Park & Hong Kong Island & $22.277658,114.162057$ & No \\
\hline Aldrich Bay Park & Hong Kong Island & $22.282800,114.224999$ & No \\
\hline Aberdeen Country Park & Hong Kong Island & $22.282924,114.225162$ & No \\
\hline Wong Nai Chung Reservoir Park & Hong Kong Island & $22.282924,114.225162$ & No \\
\hline Tai Tam Tuk Reservoir & Hong Kong Island & $22.282924,114.225162$ & No \\
\hline
\end{tabular}


urogenital schistosomiasis has been detected in different parts of Europe, primarily in travellers returning from endemic areas where they have been exposed to water containing cercariae of $S$. haematobium [9-12]. Recently, S. haematobium was introduced into the island of Corsica and became established in the local populations of Bulinus truncatus. This resulted in a number of local people and tourists becoming infected with urogenital schistosomiasis [9-11]. Previous studies have revealed that the schistosomiasis prevalence rate in subSaharan African immigrants during 2000-2009 in Spain was $~ 5.9 \%(n=317)$, while the Hospital for Tropical Diseases in the United Kingdom diagnosed 1020 schistosomiasis cases in travellers returning from Africa between 1997 to 2012; S. haematobium was the predominant species in those with schistosomiasis confirmed by microscopy $(74.2 \%, 204 / 252)[13,14]$.

In 2012, the Guangdong Provincial Center for Disease Control and Prevention (CDC) performed a survey and recorded $B$. straminea in the water areas of Shenzhen and most of the rivers in the Lo $\mathrm{Wu}$ area (which is the border between Hong Kong and mainland China). A recent survey has further supported that $B$. straminea and $B$. kuhniana (the latter is thought to be incompatible with S. mansoni) can be found in different regions in the southern part of China - Guangdong [15], suggesting a

Table 2 The accession numbers of sequences used in this study

\begin{tabular}{|c|c|c|c|}
\hline Sample & $\operatorname{cox} 1$ & 165 & ITS1-5.8S-ITS2 \\
\hline P. trivolvis & AY227371.1 & AY030234.1 & AY030403.1 \\
\hline B. glabrata isolate VG3 & JQ886409.1 & & \\
\hline B. glabrata 1 & & & AY030377.1 \\
\hline B. glabrata & & AY198095.1 & \\
\hline B. glabrata 2 & & & AY030376.1 \\
\hline B. glabrata 3 & & & AY030375.1 \\
\hline B. glabrata 4 & & & AY030374.1 \\
\hline B. straminea strain 1107 & AF199085.1 & & \\
\hline B. straminea-Brazil 2 & & AY030213.1 & AY030381.1 \\
\hline B. straminea LBMSU431 & KF926118.1 & & \\
\hline B. straminea-Brazil 1 & & AY030214.1 & AY030382.1 \\
\hline B. prona & & AY030222.1 & AY030391.1 \\
\hline B. tenagophila & AF199089.1 & AY030220.1 & AY030387.1 \\
\hline B. amazonica & & AY030217.1 & AY030385.1 \\
\hline B. pfeifferi & AF199105.1 & AY030194.1 & AY030364.1 \\
\hline B. sudanica & AF199109.1 & DQ084861.1 & AY030369.1 \\
\hline B. camerunensis & DQ084827.1 & AY030198.1 & AY030367.1 \\
\hline B. kuhniana Colombia & & AY030211.1 & \\
\hline B. kuhniana SZX1 & KJ137287.1 & KJ137293.1 & \\
\hline B. kuhniana & & & AY030380.1 \\
\hline B. kuhniana Venezuela & & AY030212.1 & \\
\hline
\end{tabular}

surveillance-response system is required. Trading and travel between different places in the globe, and especially between Guangdong and Hong Kong, have been increasing rapidly in the last decades after the handover. Many businessmen, workers and tourists may visit schistosomiasis-endemic areas and become infected; it is the movement of people that provides the opportunity for the parasite to be introduced into a new area. Even when good sanitation exists, it is possible that the local water could become contaminated by bathing or defecation. If a compatible snail host is present, there is a chance of transmission becoming established.

Table 3 The accession numbers of the sequences generated in this study

\begin{tabular}{|c|c|c|c|}
\hline Sample & $\operatorname{cox} 1$ & $16 S$ & ITS1-5.8S-ITS2 \\
\hline LW1 & KY697197 & KY697220 & \\
\hline LW2 & KY697198 & KY697221 & KY684232 \\
\hline LW3 & KY697199 & KY697222 & \\
\hline HKL2 & KY697200 & KY697223 & KY684234 \\
\hline HKL3 & KY697201 & KY697224 & \\
\hline HKL10 & KY697202 & KY697225 & \\
\hline PCL1 & KY697203 & KY697226 & \\
\hline PCL2 & KY697204 & KY697227 & KY684238 \\
\hline PCL3 & KY697205 & KY697228 & KY684239 \\
\hline SSH1 & KY697206 & KY697229 & \\
\hline $\mathrm{SSH} 2$ & KY697207 & KY697230 & KY684241 \\
\hline $\mathrm{SSH} 3$ & KY697208 & KY697231 & \\
\hline NgT1 & KY697209 & KY697232 & KY684243 \\
\hline NgT2 & KY697210 & KY697233 & KY684244 \\
\hline $\mathrm{NgT3}$ & KY697211 & KY697234 & KY684245 \\
\hline SB1 & KY697212 & KY697235 & \\
\hline SB3 & KY697213 & & \\
\hline SG1 & KY697214 & KY697236 & KY684246 \\
\hline SG3 & KY697215 & & KY684247 \\
\hline SG4 & KY697216 & KY697238 & KY684248 \\
\hline JP11 & KY697217 & KY697239 & KY684249 \\
\hline JP12 & KY697218 & KY697240 & KY684250 \\
\hline JP13 & KY697219 & KY697241 & KY684251 \\
\hline DP2 & KY697246 & KY697245 & KY690168 \\
\hline DP1 & KY697247 & KY697244 & KY690167 \\
\hline DG11 & KY697248 & KY697242 & KY690165 \\
\hline DG12 & KY697249 & KY697243 & KY690166 \\
\hline ZD2 & KY697250 & & \\
\hline ZD1 & KY697251 & & \\
\hline LD4 & KY697252 & & \\
\hline LD5 & KY697253 & & \\
\hline LD6 & KY697254 & & \\
\hline
\end{tabular}


Indeed, back in 1970s, the occurrence of B. straminea was first reported at Lam Tsuen valley in Hong Kong [16], and snails have since been identified at different places in Hong Kong and Guangdong Province [17-19]. Molecular (mainly allozyme electrophoresis) and field studies in those days suggested that there could have been multiple introductions of this species to Hong Kong via imported tropical aquarium plants or fish from South America [18, 19]. From 1979 to 2011, imported schistosomiasis cases (total 426) continued to be reported in China, and $~ 69 \%$ (294) of them were reported after 2000 [20]. The snail B. straminea can be relatively fast spreading (i.e. lays as many as $\sim 70$ eggs/snail/day), and is tolerant of drought for more than 30 days [21]. These features give it the potential for dispersal between Hong Kong and other areas in China, such as by attaching to floating items and transfer from one city to another during storms (e.g. $[15,16,19])$. However, there has not been any systematic monitoring programme or vigilance for $B$. straminea's migration and current status in Hong Kong.

It is evident that the situation regarding the current geographical distribution, evolutionary history and infection of B. straminea by S. mansoni, is poorly known in contemporary Hong Kong. The present study carried out from July 2016 to January 2017 revealed that at least eight locations in the New Territories in Hong Kong contained B. straminea. Moreover, a variant strain of $B$. straminea with red-coloured shells was discovered. Although the snails collected in the field were found not to be infected with $S$. mansoni, this study confirms the continued existence of Neotropical schistosomiasistransmitting snails in contemporary Hong Kong, and warrants the monitoring and understanding of the biology of this intermediate host between the borders of mainland China and Hong Kong.

\section{Methods}

\section{Specimen collection}

Hong Kong is a place with a great variety of habitats, including grasslands, shrublands, woodlands, hilltops, streams, ponds, wetlands, agricultural fields and urban areas. The climate is sub-tropical, and there are usually heavy rainfalls and tropical cyclones from June to October. Snails with shell morphology similar to $B$. straminea were collected from rivers, ditches and reservoirs in different parts of Hong Kong from July 2016 to January 2017. For safety measures, researchers wore rubber gloves and Wellington boots to prevent direct skin contact with water and snails. Specimens were labeled with collection locality, GPS coordinates, date and collector, and transported to the laboratory for storage in $95 \%$ ethanol; these data are summarized in Table 1.

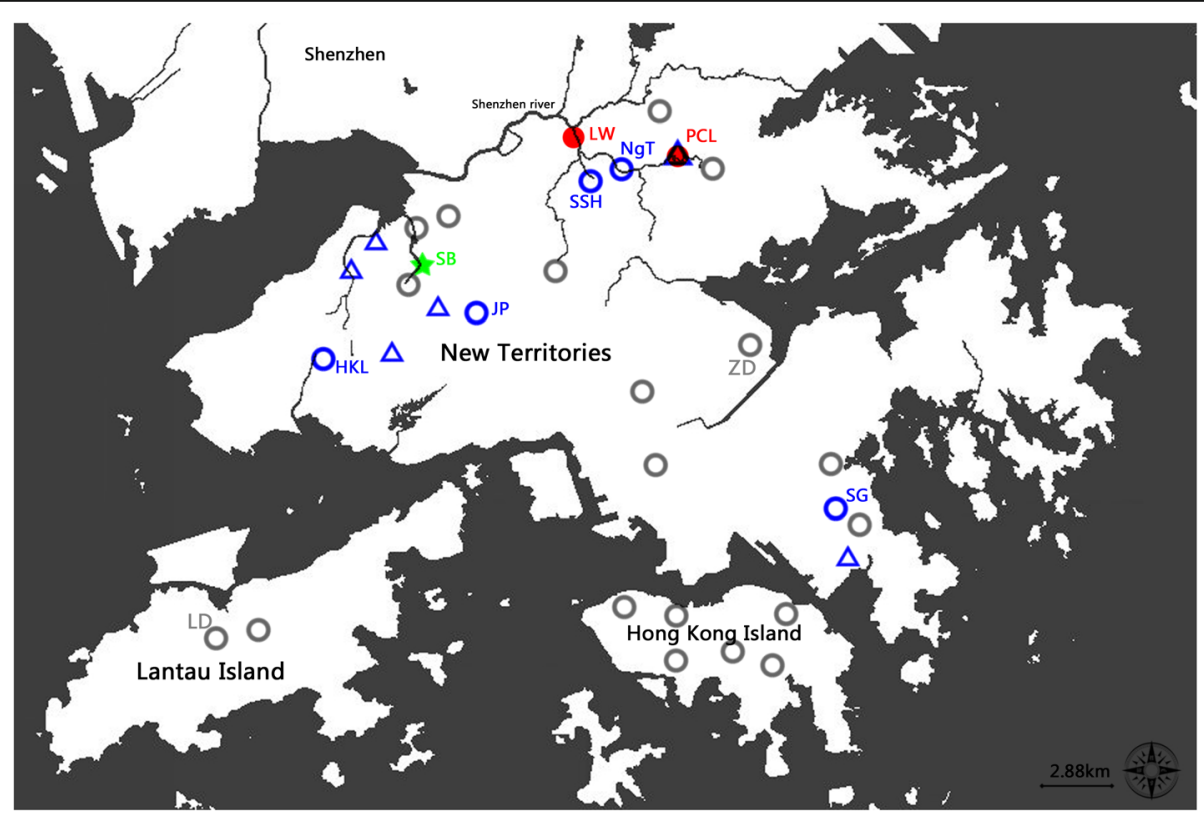

Fig. 1 The geographical distribution of B. straminea in Hong Kong. The grey circles denote sites where B. straminea was absent; ZD and LD (marked in grey) represent sites containing snails with morphological resemblance to $B$. straminea, which were not $B$. straminea as suggested by the molecular data (i.e. false positive sites). The blue circles represent the $B$. straminea-positive sites whereas only black shell snails were found. The red dots represent B. straminea-positive sites with coexistence of red-and black- shelled snails. The green pentacle represents a site with only dead snails and shells found (proven to be B. straminea by molecular data). The blue triangles represent sites containing B. straminea reported in the 1980s [18]. Note that the site PCL contains B. straminea in both the present and previous studies 
Anatomical and molecular identification of $B$. straminea Snails collected from each location were dissected for anatomical identification under a microscope [22]. In brief, shells of snails were carefully removed with forceps and the number of prostate diverticula were counted under the microscope as previously described [22]. Genomic DNA was further extracted from $~ 10-30 \mathrm{mg}$ foot tissue of snails examined above using QIAamp DNA Mini Kit (Qiagen, Hilden, Germany). DNA sequencing of individual cytochrome $c$ oxidase subunit 1 (cox1) [23], internal transcribed spacer 1 (ITS1), 5.8S rDNA, and internal transcribed spacer 2 (ITS2), and $16 \mathrm{~S}$ ribosomal DNA (rDNA) was carried out as previously described [24, 25]. All 3 markers were amplified under the same PCR temperature profile: an initial $5 \mathrm{~min}$ denaturation step at $94{ }^{\circ} \mathrm{C}$ followed by 30 cycles (iterations of $50 \mathrm{~s}$ at $94{ }^{\circ} \mathrm{C}, 50 \mathrm{~s}$ at $55{ }^{\circ} \mathrm{C}$ and $50 \mathrm{~s}$ at $72{ }^{\circ} \mathrm{C}$ ) plus a final $10 \mathrm{~min}$ extension at $72{ }^{\circ} \mathrm{C}$. Gel electrophoreses were performed to confirm successful amplification of the desired fragment of the target size. PCR products were purified using the QIAquick PCR Product Purification Kit (Qiagen, Hilden, Germany). Sequences of purified PCR products were obtained from both directions using the same primer pair for PCR by cycle sequencing in a commercial laboratory (BGI Tech Solutions (Hong Kong) Co., Ltd., Beijing, China).

\section{Phylogenetic analyses of $B$. straminea}

The cox1, ITS1-5.8S-ITS2 and 16S rDNA sequences obtained above and those available at the NCBI databases (Tables 2,3) were aligned and concatenated using MEGA7 [26], and phylogenetic trees were constructed using the Neighbour-Joining method with model selection (Kimura 2-parameter method + Gamma distribution) determined by MEGA7 [27]. All trees were evaluated using 1000 nonparametric bootstraps.

\section{Detection of S. mansoni by both biopsy and molecular analyses}

Field-collected snails were dissected under the microscope to look for any evidence of S. mansoni. In addition, a more reliable and sensitive molecular method specifically targeting the $S$. mansoni $16 \mathrm{~S}$ rDNA sequence was employed. The following PCR temperature profile was used: an initial cycle of 5 min denaturation at $94{ }^{\circ} \mathrm{C}$, followed by 40 iterations of $50 \mathrm{~s}$ at $94{ }^{\circ} \mathrm{C}, 50 \mathrm{~s}$ at $55{ }^{\circ} \mathrm{C}$ and $50 \mathrm{~s}$ at $72{ }^{\circ} \mathrm{C}$, and ended with $10 \mathrm{~min}$ extension at $72{ }^{\circ} \mathrm{C}$. Gel electrophoreses were performed to confirm successful amplification of the genomic fragments with expected target size. PCR products were purified using the QIAquick PCR Product Purification Kit (Qiagen).
Sequences of purified PCR products were obtained from both directions using the same primer pair for PCR by cycle sequencing in a commercial laboratory (BGI Tech Solutions (Hong Kong) Co., Ltd.).

\section{Results}

The distribution of Biomphalaria straminea in Hong Kong

Taking into account the previous reports of B. straminea in Hong Kong back in the 1970s, a total of 27 freshwater locations in Hong Kong including 19 in the New Territories, 2 on Lantau Island and 6 on Hong Kong Island were visited between July 2016 and January 2017 (Table 1). Given that snails were collected based on morphological appearance, false positives were identified in sites such as the Tung Chung River and The Chinese University of Hong Kong on the basis of their cox 1 sequences (see next section). Detailed anatomical and molecular analyses confidently indicated 8 positive sites containing $B$. straminea; these were widespread in the New Territories (NT) (i.e. 5 in northern NT close to the border to

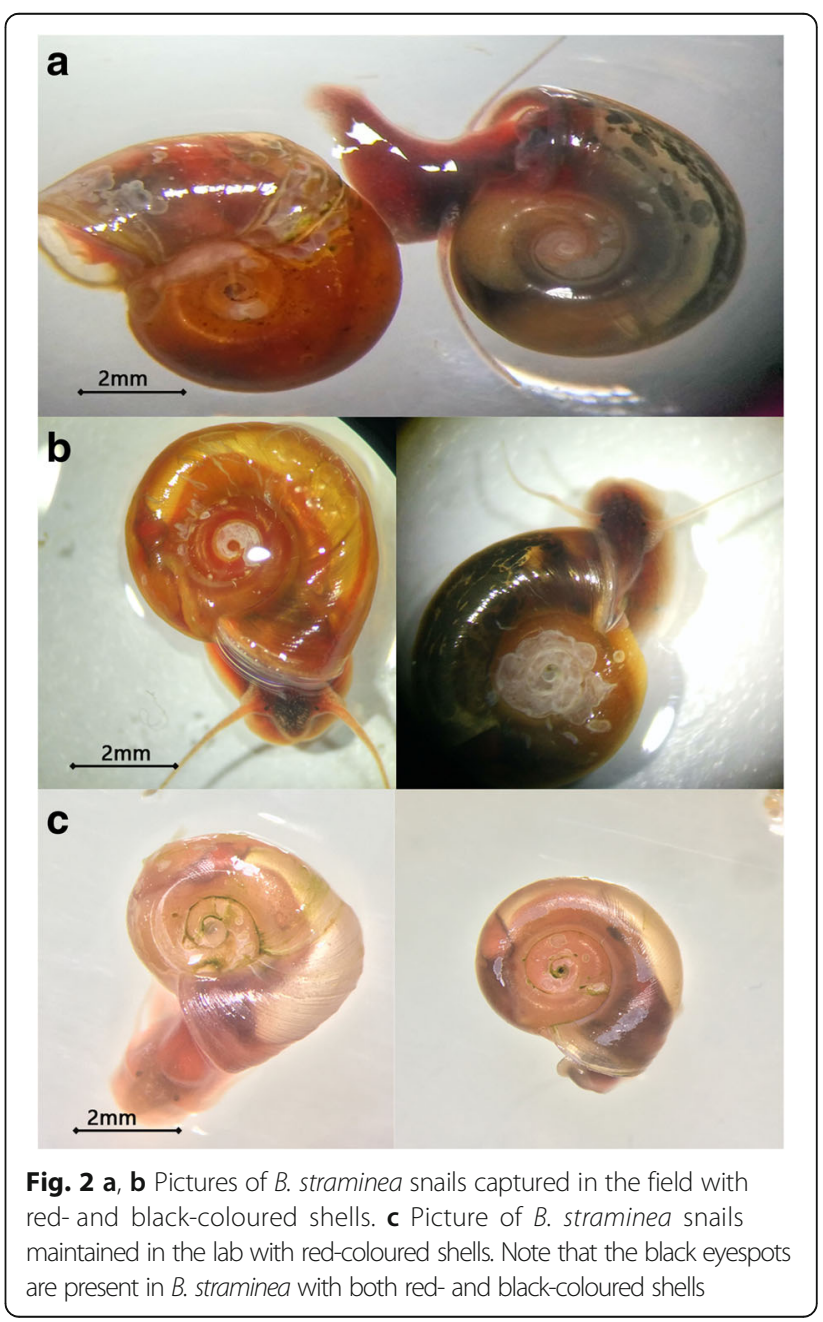


mainland China, 1 in south-western NT, 1 in central NT, and 1 in south-eastern NT) (Fig. 1).

Black-coloured shell B. straminea were identified for all these 8 positive sites (Fig. 2); while red-coloured shell $B$. straminea were also found to coexist in certain locations, including the Lo Wu Border (LW) (i.e. the border between Hong Kong and mainland China) and Ping Che Road (PCL). In some locations, such as the one in Shan Pui River 1 (SB), only dead snails and empty shells could be found.

Snails collected from in the field were cultured and allowed to breed in the laboratory (Fig. 3). Preliminary observations showed that adults with red-coloured shells caught from the wild produced offspring with red shells, while the first-generation offspring of black-shelled snails were either all with black shells or a mixture of individuals with black or red shells. Black eyespots were observed for both red-shelled and black-shelled B. straminea (Fig. 2b, c). Although a more detailed and mass-scale breeding exercise will be required to determine if this phenotype is controlled by a single allele, these observations supported the hypothesis that the red-shelled and black-shelled $B$. straminea do crossbreed in nature.

\section{Species identification of $B$. straminea}

Both molecular analysis on cytochrome $c$ oxidase subunit 1 ( $\operatorname{cox} 1)$ sequences and anatomical analysis on prostate diverticula (Fig. 4) were applied to determine whether the specimens were bona fide $B$. straminea as previously described $[22,23]$. As mentioned in the previous section, except for the snails collected from sites at the Tung Chung River (Lantau Island) and the Chinese University of Hong Kong (New Territories), all cox1 sequences proved to be similar to the Biomphalaria straminea cox1 sequence deposited on NCBI (GenBank: AF199085.1) (Fig. 5). For the other species, BlastN searches on the NCBI database revealed that one of the three samples collected at the Tung Chung River had 93\% sequence similarity to Hippeutis cantori (GenBank: KC135955.1), while the two other samples collected from Tung Chung River and two samples collected from the Chinese University of Hong Kong all showed 99\% sequence similarity to Gyraulus sp. (GenBank: KC495769.1). In addition, anatomical analyses were also carried out following the criteria of a previous study to differentiate $B$. straminea from $B$. kuhniana (a subspecies in B. straminea) [22], where the number of prostate diverticula in $B$. straminea are between 10 and 20 (average of 14.28,

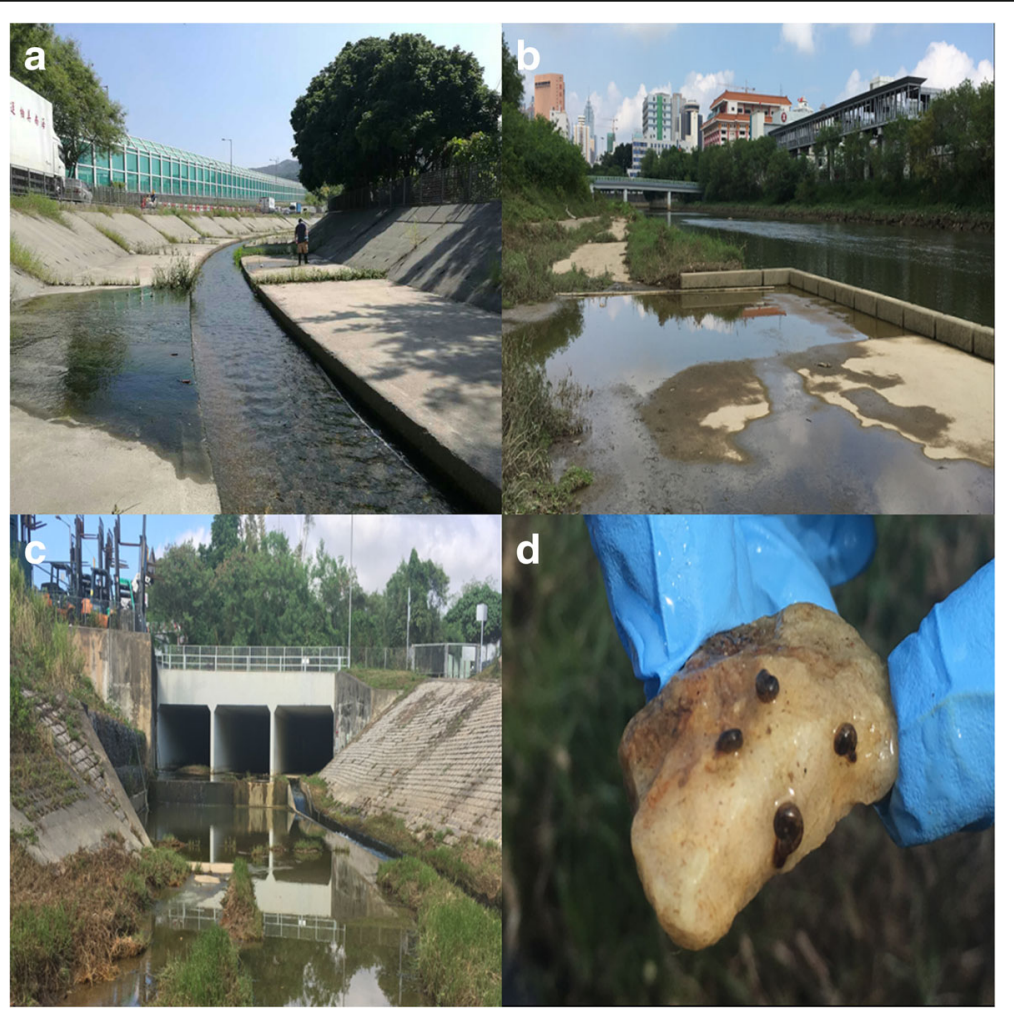

Fig. 3 Pictures representing the typical habitats of snails B. straminea identified in Hong Kong. a Ditch in the Fu Hang Road (HKL). b River in the Lo Wu Border (LW). c Drainage exit in Ping Che Road (PCL). d Four B. straminea attached on a small rock collected in the field 


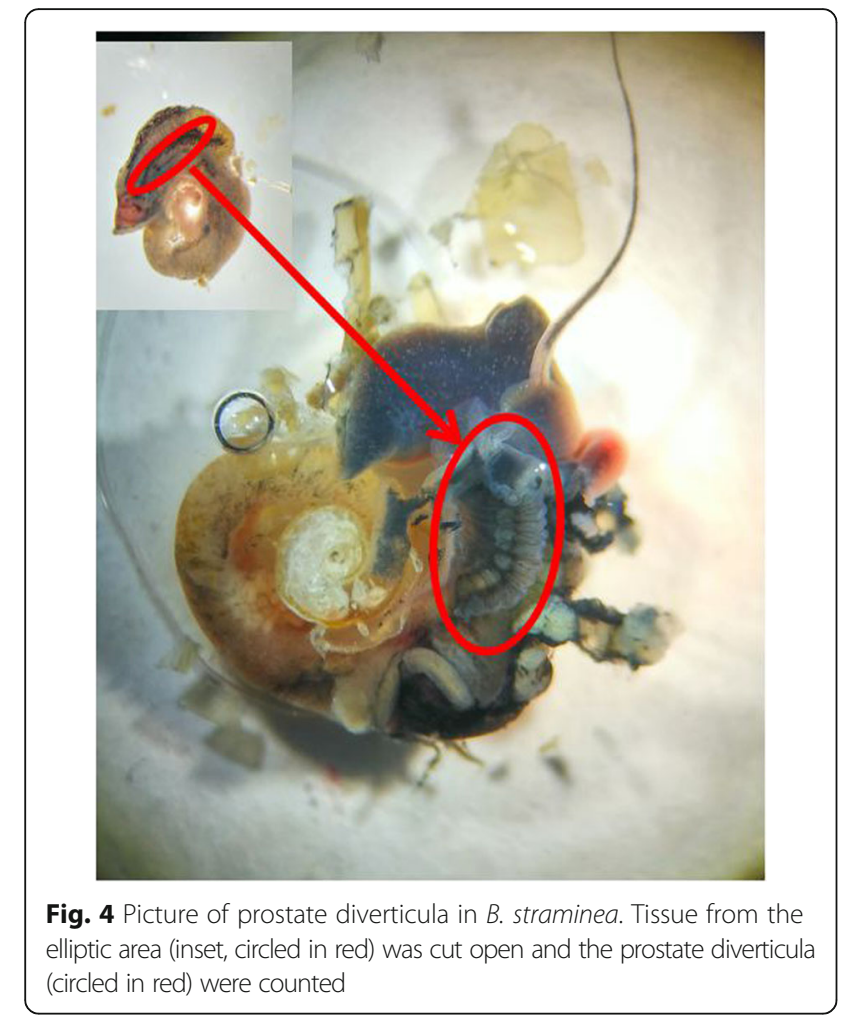

Table 4) and those in B. kuhniana are between 4 to 7. We examined the prostate diverticula of all these snails, except the ones collected from site SB which were decomposed (Table 4). All of these were found to fit the numbers for B. straminea, and hence, the combination of anatomical and molecular evidence indicates that they were all B. straminea.

\section{Phylogenetic analysis of $B$. straminea}

Cox1, ITS1-5.8S-ITS2, and 16S rDNA were used as genetic markers in phylogenetic analyses of the $B$. straminea snails in Hong Kong. Maximum-likelihood trees based on individual markers demonstrated the $B$. straminea snails in Hong Kong were very similar to the Brazilian strain (Figs. 5, 6, 7; Additional file 1: Fig. S1, Additional file 2: Fig. S2 and Additional file 3: Fig. S3). Using the concatenated sequences from all three markers in constructing the phylogenetic trees resulted in the same result (Fig. 8; Additional file 4: Fig. S4), suggesting that the B. straminea snails in Hong Kong are likely derived from South America. The genetic distance tables are shown in Additional file 5: Tables S1, Additional file 6: Tables S2, Additional file 7: Tables S3 and Additional file 8: Tables S4).

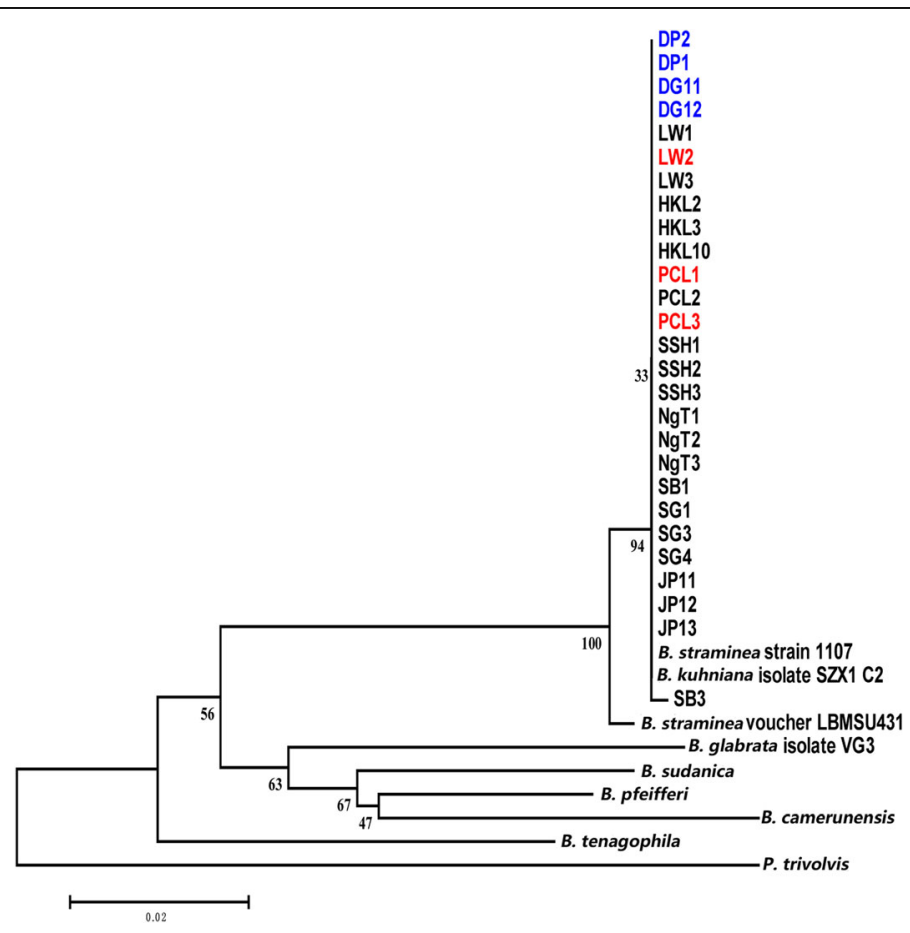

Fig. 5 Neighbour-joining tree constructed based on K2P + G model for cox1 sequences (549 nt) of B. straminea samples collected from different sites in Hong Kong. The abbreviated names and numbers denote the samples collected from the sites listed in Table 1. Red colour represents $B$. straminea with red-coloured shells. DP1, DP2, DG11 and DG12 (marked in blue) represent B. straminea collected in cities outside Hong Kong (Shenzhen (DP) and DongGuan (DG) in the mainland China 
Table 4 The number of prostate diverticula of the examined $B$ straminea captured from the field

\begin{tabular}{|c|c|c|}
\hline Sample code & PDN & APDN \\
\hline$\overline{P C L 1}$ & 14 & 13 \\
\hline PCL2 & 12 & \\
\hline PCL3 & 13 & \\
\hline LW1 & 16 & 14.67 \\
\hline LW2 & 14 & \\
\hline LW3 & 14 & \\
\hline SSH1 & 14 & 16.33 \\
\hline $\mathrm{SSH} 2$ & 17 & \\
\hline $\mathrm{SSH} 3$ & 18 & \\
\hline JP11 & 13 & 11.67 \\
\hline$J P 12$ & 11 & \\
\hline$J P 13$ & 11 & \\
\hline SG1 & 14 & 12.67 \\
\hline SG3 & 12 & \\
\hline SG4 & 12 & \\
\hline HKL2 & 14 & 12.67 \\
\hline HKL3 & 12 & \\
\hline HKL10 & 12 & \\
\hline $\mathrm{NgT1}$ & 19 & 17.67 \\
\hline $\mathrm{NgT2}$ & 18 & \\
\hline $\mathrm{NgT3}$ & 16 & \\
\hline All & & 14.28 \\
\hline
\end{tabular}

Abbreviations: PDN prostate diverticula number, $A P D N$ average prostate diverticula number
The infection status of $B$. straminea by Schistosoma mansoni Both the biopsy and molecular analyses using PCR primers specific for the $S$. mansoni $16 \mathrm{~S}$ rDNA on $B$. straminea DNA gave negative results. A total of 87 individual snails were tested alongside the positive control which comprised DNA extracted from $S$. mansoni. Only the positive control was found to have a DNA fragment of $256 \mathrm{bp}$ amplified when examined under the agarose gel, and all 87 samples tested were found to be negative (Fig. 9).

\section{Discussion}

\section{Existence of $B$. straminea in contemporary Hong Kong}

This study investigated the geographical distribution of Biomphalaria straminea in Hong Kong, its current infection status and revealed the phylogenetic relationships with those found in other parts of the world. The value of this study lies in determining the current distribution of these snails, which have the potential to transmit $S$. mansoni in contemporary Hong Kong. It is more than 30 years since the previous studies, and thus it is essential to evaluate the potential risk of the co-existence of $B$. straminea and the introduction of infection, i.e. infected individuals with $S$. mansoni, resulting in triggering the transmission cycle in the places concerned.

During this study carried out between July 2016 and January 2017, B. straminea was found in different districts in the New Territories, including the border

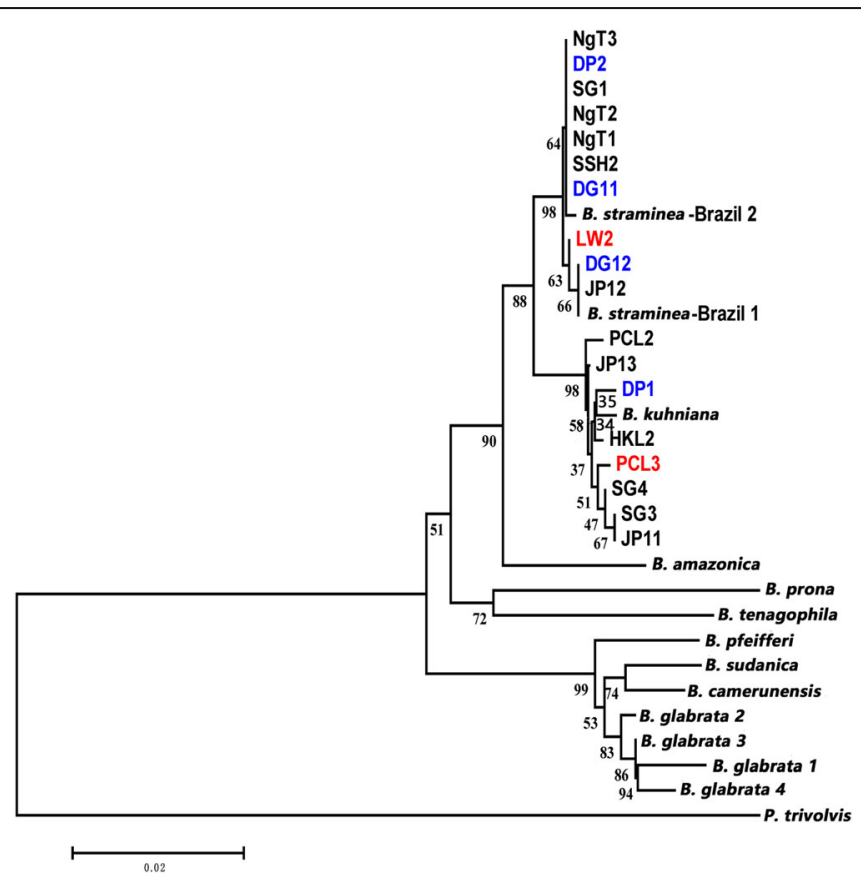

Fig. 6 Neighbour-joining tree constructed based on K2P + G model for ITS1-5.8S-ITS2 sequences (914 nt) of B. straminea samples collected from different sites in Hong Kong. The abbreviated names and numbers denote the samples collected from the sites listed in Table 1. Red colour represents B. straminea with red-coloured shells. DP1, DP2, DG11 and DG12 (marked in blue) represent B. straminea collected in cities outside Hong Kong (Shenzhen (DP) and DongGuan (DG) in the mainland China 


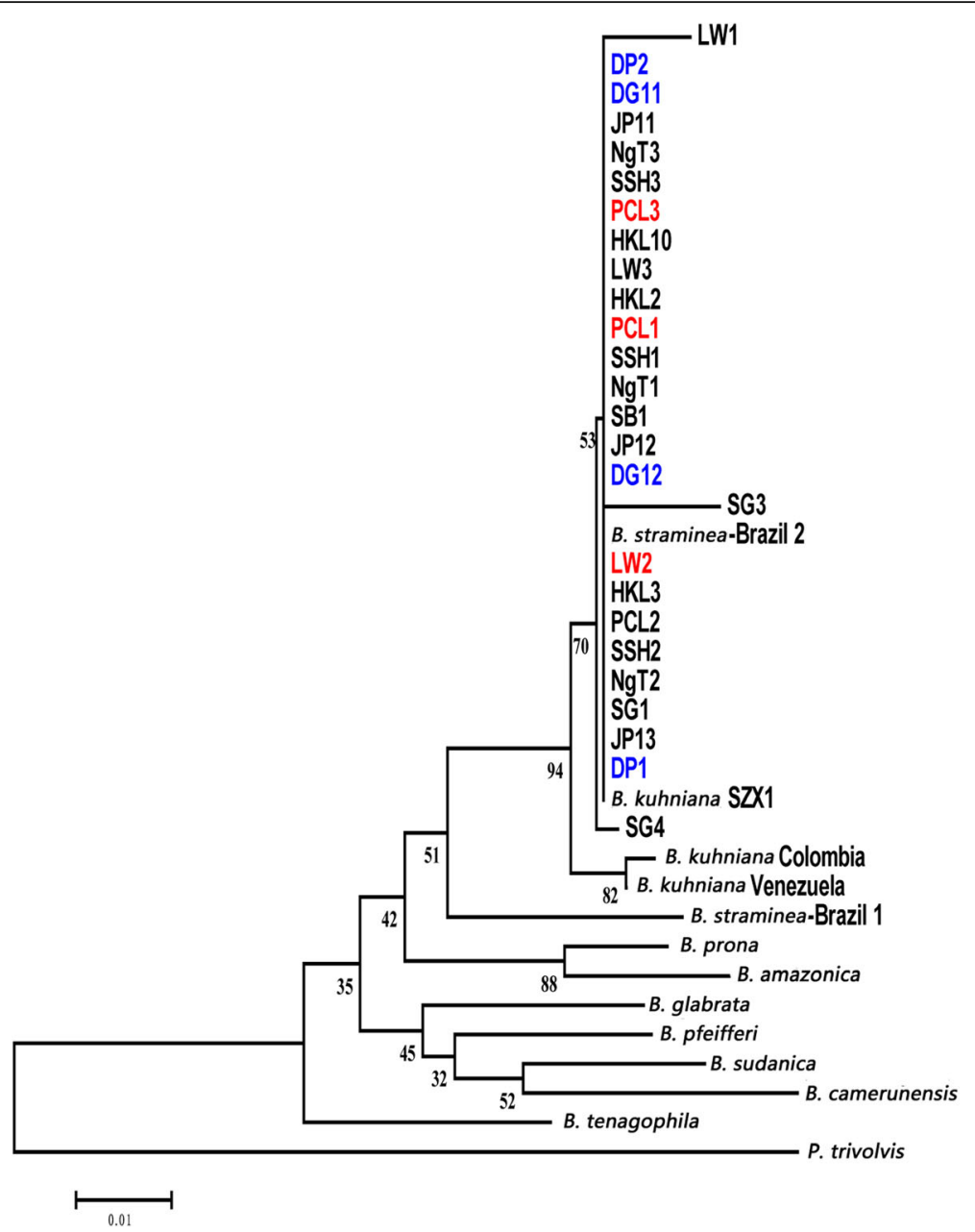

Fig. 7 Neighbour-joining tree constructed based on K2P + G model for 165 rDNA sequences (343 nt) of B. straminea samples collected from different sites in Hong Kong. The abbreviated names and numbers denote the samples collected from the sites listed in Table 1. Red colour represents B. straminea with red-coloured shells. DP1, DP2, DG11 and DG12 (marked in blue) represent B. straminea collected in cities outside Hong Kong (Shenzhen (DP) and DongGuan $(D G)$ in the mainland China

between Hong Kong and mainland China. These districts include habitats which were not reported 30 years ago. Given there has been no systematic survey of snails in these districts in previous decades, and the New Territories have also been rapidly developed, it is not possible to determine whether the current population of $B$. straminea has been spreading and expanding in the last 30 years. On the other hand, highly urbanized and isolated areas, such as those in Hong Kong Island, where no signs of B. straminea could be detected, suggest a potential influence of urbanization on the snail's habitat and distribution.

In the Shan Pui River 1 (SB), which is located near the estuary, only dead B. straminea or their empty shells could be found. If this observation was solely due to the influx of seawater, this would be indicative that $B$. straminea could not survive in brackish water, despite a previous report that concluded that
B. straminea was more tolerant to both salinity and lack of freshwater than other Biomphalaria species [21].

\section{Red- and black-shelled B. straminea in Hong Kong}

The identification of two shell colours of $B$. straminea contrasts with the previous field investigations in Hong Kong; either the colour variants were missed in the earlier studies or a new phenotype has evolved in the last 30 years [14, 15, 28-30]. A previous pigmentation study supported the existence of $B$. straminea with both shell colours [31]. Pigmentation effect has been better studied in another Biomphalaria species, B. glabrata, and temperature is one of the factors determining melanic and albino variants [32-34]. Nevertheless, given that black eyespots were observed in red shelled $B$. straminea (Fig. 2), the genetic mutation responsible is likely to be different from true albinos. 


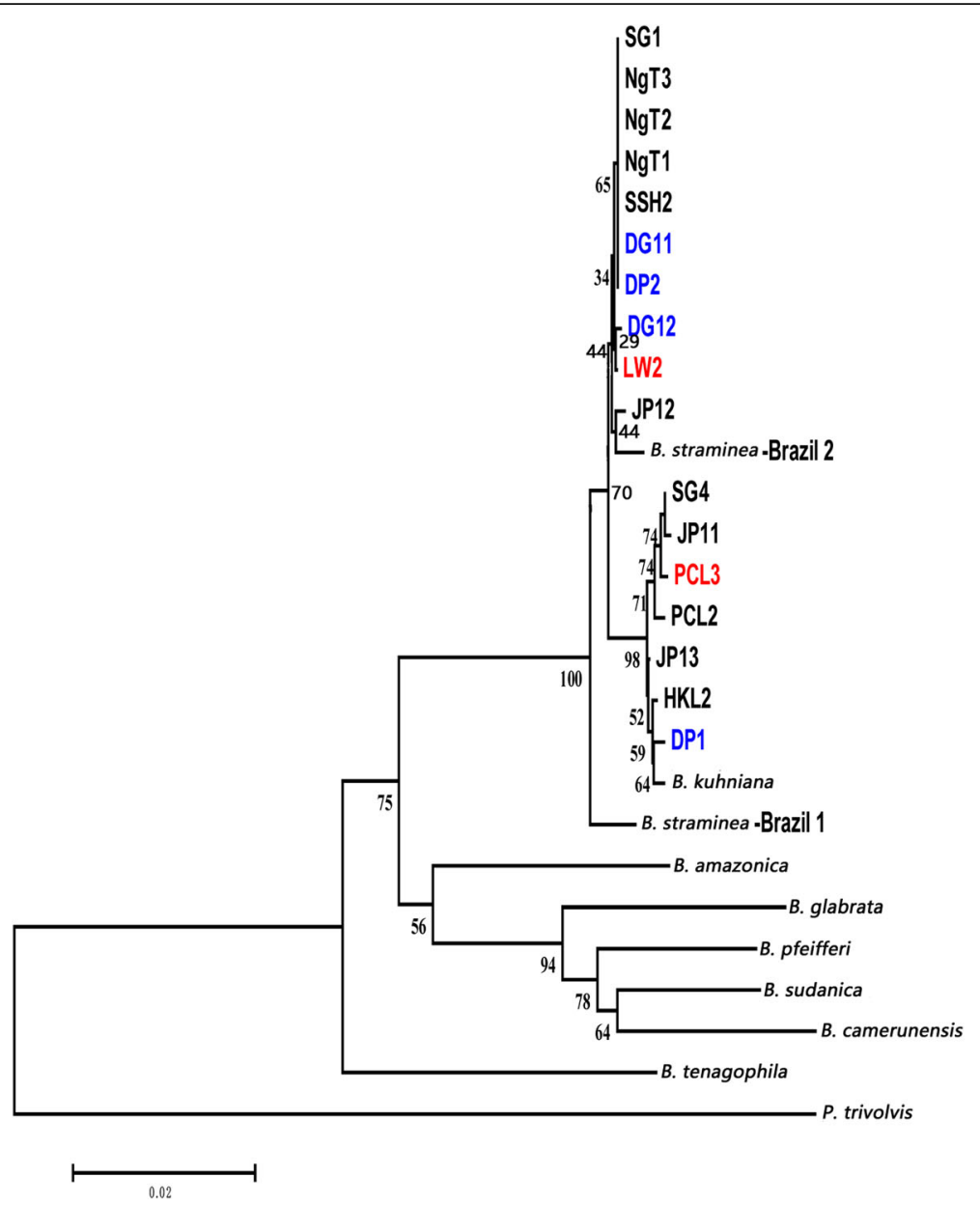

Fig. 8 Neighbour-joining tree constructed based on K2P + G model for concatenated cox1, ITS1-5.8S-ITS2 and 16S rDNA sequences (1779 nt) of B. straminea samples collected from different sites in Hong Kong. The abbreviated names and numbers denote the samples collected from the sites listed in Table 1. Red colour represents B. straminea with red-coloured shells. DP1, DP2, DG11 and DG12 (marked in blue) represent B. straminea collected in cities outside Hong Kong (Shenzhen (DP) and DongGuan (DG) in the mainland China

\section{Genetic structure of $B$. straminea in Hong Kong}

A recent survey on the distribution of Biomphalaria spp. in mainland China suggested the presence of two genetically close species, B. straminea and B. kuhniana, in Guangdong Province (southern part of mainland China

\section{$\begin{array}{lllllll}1 & 2 & 3 & 4 & 5 & 6 & 7\end{array}$}

Fig. 9 Example of PCR amplifying S. mansoni specific 165 rDNA sequence on gDNA extracted from: Lanes 1, 2: S. mansoni adult worms (as positive controls); Lane 3: field-captured B. straminea with a black-coloured shell; Lane 4: field captured B. straminea with a red-coloured shell; Lane 5: laboratory cultured $B$. straminea with a black-coloured shell; Lane 6: laboratory cultured B. straminea with a red-coloured shell; Lane 7: negative control. All 87 tested individuals were found to be negative for $S$. mansoni infection and connected to the border of Hong Kong) [15]. Given the two species have different abilities to transmit $S$. mansoni (B. kuhniana is thought to be incapable), anatomical analysis was first employed, revealing the average number of prostate diverticula to be 14.28 (Table 4), indicating that the snails were $B$. straminea and not $B$. kuhniana. The phylogenetic relationships of $B$. straminea snails collected in the present study were assessed using a combination of 16S ribosomal DNA, 18S ribosomal DNA + internal transcribed spacer $1+5.8 \mathrm{~S}$ ribosomal DNA + internal transcribed spacer $2+28 \mathrm{~S}$ ribosomal DNA and cox 1 region markers [35-37] and the results clearly showed that the snails collected in Hong Kong are genetically indistinguishable, similar to those in mainland China, and phylogenetically close to those from Brazil in South America (Fig. 8). All these data suggest that the $B$. straminea snails in Hong Kong and maybe also mainland China are likely derived from South America. 


\section{Potential risk of schistosomiasis?}

Recent studies have shown that Biomphalaria snails including B. straminea in the Guangdong Province, southern part of mainland China closest to the border of Hong Kong, had been expanding their range from isolated sites in Shenzhen, not only to all districts in Shenzhen including Dongguan and Huizhou cities, but to the entrance of the East Branch of Pearl River $[28,29]$. It has also been predicted that B. straminea will spread to Pearl River Delta areas in Guangdong, southern parts of Guangxi and Fujian provinces, as well as the North of Taiwan [30]. These data suggest that the $B$. straminea situation should be closely monitored.

Ever since the first report of identification of B. straminea in Hong Kong back in the 1970s, there have always been concerns about $S$. mansoni infection breakouts southern China [14-20, 28-30]. In the north-east of Brazil, the prevalence of $S$. mansoni infection in B. straminea ranges from 11 to $24 \%$ [38, 39], while artificial exposures of $S$. mansoni to B. straminea in the laboratory have shown low infectivity, with prevalence ranging from 1.2 to $1.6 \%$ depending on the strain of miracidia being tested [40]. Close to the border between Hong Kong and mainland China, in the city of Shenzhen, a recent study reported that the black-coloured $B$. straminea collected in the field were resistant to S. mansoni infection [41]. All 87 individuals collected from the field and analysed in this study were found to be negative for $S$. mansoni but the susceptibility of cultured snails to infection in the laboratory with $S$. mansoni remains to be tested.

In 2016, there were more than 56 million visitors worldwide travelling to Hong Kong including those from S. mansoni-endemic countries. The number of trips for people travelling between Hong Kong and mainland China was also more than 77 million per year. The potential risk of introducing and spreading schistosomiasis exists. Yet, without knowing the biology of the vector $B$. straminea, such as its transmission ability in Hong Kong and mainland China when compared to those reported in Brazil for instance, it is difficult to determine the actual risk (i.e. high, medium, low, or negligible). Nevertheless, given the increasing range of $B$. straminea, an updated strategy is required to minimize the risk of spreading schistosomiasis; such a strategy could include surveillance of potentially infected migrants or overseas workers, regulating the import of freshwater plants, and snail control using molluscicides in potential transmission sites.

\section{Conclusions}

This study revealed the presence of $B$. straminea in different districts in the New Territories of Hong Kong, including places close to the border connecting to mainland China. None of the B. straminea investigated in this study were found to be infected with $S$. mansoni. The Hong Kong B. straminea are genetically indistinguishable, based on the chosen markers, and resemble those from South America.

\section{Additional files}

\begin{abstract}
Additional file 1: Figure S1. Maximum-likelihood tree constructed based on Hasegawa-Kishino-Yano model + G model for cox1 sequences (549 nt) of B. straminea samples collected from different sites in Hong Kong. The abbreviated names and numbers denote the samples collected from the sites listed in Table 1. Red colour represents B. straminea with red-coloured shells. DP1, DP2, DG11 and DG12 (marked in blue) represent B. straminea collected in cities outside Hong Kong (Shenzhen (DP) and DongGuan (DG) in the mainland China. (PDF $184 \mathrm{~kb}$ )
\end{abstract}

Additional file 2: Figure S2. Maximum-likelihood tree constructed based on K2P + G model for ITS1-5.8S-ITS2 sequences (914 nt) of B. straminea samples collected from different sites in Hong Kong. Abbreviations are as in Figure S1. (PDF $186 \mathrm{~kb}$ )

Additional file 3: Figure S3. Maximum-likelihood tree constructed based on Tamura 3-parameter + G model for 165 rDNA sequences (343 nt) of B. straminea samples collected from different sites in Hong Kong. Abbreviations are as in Figure S1. (PDF $185 \mathrm{~kb}$ )

Additional file 4: Figure S4. Maximum-likelihood tree constructed based on General Time Reversible + G + I model for concatenated cox1, ITS1-5.8S-ITS2 and 16S rDNA sequences (1779 nt) of B. straminea samples collected from different sites in Hong Kong. Abbreviations are as in Figure S1. (PDF $185 \mathrm{~kb}$ )

Additional file 5: Table S1. Genetic distance table for cox1 sequences used in Fig. 5. (XLS 39 kb)

Additional file 6: Table S2. Genetic distance table for ITS1-5.8S-ITS2 sequences used in Fig. 6. (XLS 42 kb)

Additional file 7: Table S3. Genetic distance table for 165 rDNA sequences used in Fig. 7. (XLS 42 kb)

Additional file 8: Table S4. Genetic distance table for concatenated Cox1, ITS1-5.8S-ITS2 and 16S rDNA sequences used in Fig. 8. (XLS 37 kb)

\section{Abbreviations}

APDN: Average diverticula number; CDC: Guangdong Provincial Center for Disease Control and Prevention; cox1: cytochrome $c$ oxidase subunit 1; ITS: Internal transcribed spacer; PCR: Polymerase chain reaction; PDN: Prostate diverticula number; rDNA: ribosomal DNA

Acknowledgements

Not applicable.

\section{Funding}

This work was supported by the Hong Kong Health and Medical Research Fund (15140012) and National Research and Development Plan of China (2016YFC1200500). The funders had no roles in study design, data collection and analysis, decision to publish or preparation of the manuscript.

\section{Availability of data and materials}

Sequences data can be retrieved at the NCBI website. Details are listed in Table 3.

\section{Authors' contributions}

JHLH, ZW, MCF, QJ and DR conceived and designed the study. XZ, WCY, $K H C$ and $H Y Y$ performed the field investigation and experiments. $X Z, H Y Y$, NW, ZW and JHLH analysed the data. XZ, ZW and JHLH wrote the manuscript. All authors read and approved the final manuscript.

Ethics approval and consent to participate Not applicable. 


\section{Consent for publication}

Not applicable.

\section{Competing interests}

The authors declare that they have no competing interests.

\section{Publisher's Note}

Springer Nature remains neutral with regard to jurisdictional claims in published maps and institutional affiliations.

\section{Author details}

${ }^{1}$ School of Life Science, State Key Laboratory of Agrobiotechnology, The Chinese University of Hong Kong, Hong Kong Special Administrative Region, People's Republic of China. 'Department of Parasitology, Zhongshan School of Medicine, Sun Yat-sen University, Guangzhou, Guangdong Province, People's Republic of China. ${ }^{3}$ Key Laboratory of Tropical Disease Control (SYSU), Ministry of Education, Guangzhou, Guangdong Province, People's Republic of China. "Wolfson Wellcome Biomedical Laboratories, Department of Life Sciences, Natural History Museum, Cromwell Road, London SW7 5BD, UK. ${ }^{5}$ Department of Biology, Hong Kong Baptist University, Hong Kong Special Administrative Region, People's Republic of China.

\section{Received: 2 March 2017 Accepted: 12 July 2017}

\section{Published online: 25 July 2017}

\section{References}

1. Colley DG, Bustinduy AL, Secor WE, King CH. Human schistosomiasis. Lancet. 2014;383:2253-64.

2. Zhu R, Xu J. Epidemic situation of imported schistosomiasis in China: prevention and control. Chin J Schisto Control. 2014;26:111-4.

3. Malek EA. Snail hosts of schistosomiasis and other snail-transmitted diseases in tropical America: a manual. Washington: Pan American Health Organization Scientific Publication; 1985. p. 478.

4. Brown DS. Freshwater snails of Africa and their medical importance. 2nd ed. London: Taylor and Francis; 1994. p. 321-61.

5. Paraense WL, Corrêa LR. Probable extension of schistosomiasis mansoni to southernmost Brazil. Mem Inst Oswaldo Cruz. 1987;82:577.

6. Paraense WL, Corrêa LR. A potential vector of Schistosoma mansoni in Uruguay. Mem Inst Oswaldo Cruz. 1989:84:281-8.

7. Greer GJ, Mimpfoundi R, Malek EA, Joky A, Ngonseu E, Ratard RC. Human schistosomiasis in Cameroon. II. Distribution of the snail hosts. Am J Trop Med Hyg. 1990;42:573-80.

8. Ross AG, Bartley PB, Sleigh AC, Olds GR, Li Y, Williams GM, McManus DP. Schistosomiasis. N Engl J Med. 2002;346:1212-20.

9. Hamel MJ, Slutsker L. Schistosomiasis reaches Europe. Emerg Infect Dis. 2014:20:1595-7.

10. Berry A, Moné H, Iriart X. Schistosomiasis haematobium, Corsica. France Emerg Infect Dis. 2014:20:1595-7.

11. Holtfreter MC, Moné H, Müller-Stöver I. Schistosoma haematobium infections acquired in Corsica, France, August 2013. EuroSurveillance. 2014;19:2082.

12. Steiner F, Ignatius R, Friedrich Jaenicke B, Dieckmann S, Harms G, Poppert S, Mockenhaupt FP. Acute schistosomiasis in European students returning from fieldwork at Lake Tanganyika. Tanzania J Travel Med. 2013:20:380-3.

13. Monge-Maillo B, López-Vélez R, Norman FF, Ferrere-González F, MartínezPérez Á, Pérez-Molina JA. Screening of imported infectious diseases among asymptomatic sub-Saharan African and Latin American immigrants: a public health challenge. Am J Trop Med Hyg. 2015;92:848-56.

14. Coltart CE, Chew A, Storrar N, Armstrong M, Suff N, Morris L, Whitty CJ. Schistosomiasis presenting in travellers: a 15 year observational study at the Hospital for Tropical Diseases, London. Trans R Soc Trop Med Hyg. 2015; 109(3):214-20.

15. Attwood SW, Huo GN, Qiu JW. Update on the distribution and phylogenetics of Biomphalaria (Gastropoda: Planorbidae) populations in Guangdong Province. China Acta Trop. 2015:141:258-70.

16. Meier-Brook C. A snail intermediate host of Schistosoma mansoni introduced into Hong Kong. Bull World Health Organ. 1974;51:661.

17. Liu YY, Wang YX, Zhang WZ. The discovery of Biomphalaria straminea (dunker), an intermediate host of Schistosoma mansoni, from China. Dong Wu Fen Lei Xue Bao. 1982;7:256.

18. Dudgeon D, Yipp MW. A report on the gastropod fauna of aquarium fish farms in Hong Kong, with special reference to an introduced human schistosome host species, Biomphalaria straminea (Pulmonata: Planorbidae). Malacological Rev. 1983:16:93-4.

19. Woodruff DS, Mulvey M, Yipp MW. The continued introduction of intermediate host snails to Schistosoma mansoni into Hong Kong. Bull World Health Organ. 1985;63:621.

20. Wang W, Liang YS, Hong QB, Dai JR. African schistosomiasis in mainland China: risk of transmission and countermeasures to tackle the risk. Parasit Vectors. 2013;6:249.

21. Barboza DM, Zhang C, Santos NC, Silva MMBL, Rollemberg CW, de Amorim FJR, de Jesus AR. Biomphalaria species distribution and its effect on human Schistosoma mansoni infection in an irrigated area used for rice cultivation in northeast Brazil. Geospat Health. 2012;6:103-9.

22. Toledo R, Fried B (Editors). Biomphalaria snails and larval trematodes. Springer Science \& Business Media; 2010. p.9-13.

23. Vrijenhoek R. DNA primers for amplification of mitochondrial cytochrome $c$ oxidase subunit I from diverse metazoan invertebrates. Mol Mar Biol Biotechnol. 1994:3:294-9.

24. DeJong RJ, Morgan JA, Paraense WL, Pointier JP, Amarista M, Ayeh-Kumi PF, de Souza CP. Evolutionary relationships and biogeography of Biomphalaria (Gastropoda: Planorbidae) with implications regarding its role as host of the human bloodfluke. Mol Biol Evol. 2001;18:2225-39.

25. Palumbi SR. Nucleic acids II: the polymerase chain reaction. Molecular systematics. Sunderland, Mass: Sinauer. 1996:205-48.

26. Nei M, Kumar S. Molecular evolution and phylogenetics. New York: Oxford University Press; 2000.

27. Kumar S, Stecher G, Tamura K. MEGA7: molecular evolutionary genetics analysis version 7.0 for bigger datasets. Mol Biol Evol. 2016;33:1870-4.

28. Gao ST, Li XH, Huang SY, Xie X, Mei SJ, Ruan CW, Huang DN. Primary investigation of distribution and ecological environment of Biomphalaria straminea in Dasha and Guanlan rivers in Shenzhen areas. Chin Trop Med. 2013;13:313-7.

29. Huang SY, Zhang QM, Li XH, Deng ZH. The distribution of $B$. straminea in China and risk of transmission. Zhongguo Xue Xi Chong Bing Fang Zhi Za Zhi. 2014:3:235-7.

30. Habib MR, Guo YH, Lv S, Gu WB, Li XH, Zhou XN. Predicting the spatial distribution of Biomphalaria straminea, a potential intermediate host for Schistosoma mansoni, in China. Geospat Health. 2016;11:453.

31. Richards CS. Genetics of pigmentation in Biomphalaria straminea. Am J Trop Med Hyg. 1975;24:154-6.

32. Mulvey M, Woodruff DS, Carpenter MP. Linkage relationships of seven enzyme and two pigmentation loci in the snail Biomphalaria glabrata. J Hered. 1988;79: 473-6.

33. Iwanaga Y. In vitro cultivation of cells from ovotestis tissue of pigmented Biomphalaria glabrata. Zool Sci. 2002;19:271-4.

34. Camargo EAF, Camargo JTF, Neves MF, Simões LF, Bastos LAD, Magalhães LA, Zanotti-Magalhães EM. Assessment of the impact of changes in temperature in Biomphalaria glabrata (Say, 1818) melanic and albino variants infected with Schistosoma mansoni (Sambon, 1907). Braz J Biol. 2016;

35. Caldeira RL, Vidigal TH, Simpson AJ, Carvalho OS. Genetic variability in Brazilian populations of Biomphalaria straminea Complex detected by simple sequence repeat anchored polymerase chain reaction amplification. Mem Inst Oswaldo Cruz. 2001;96:535-44.

36. Velásquez LE, Caldeira RL, Estrada V, Carvalho OS. Morphological and polymerase chain reaction-restriction fragment lenght polymorphism characterization of Biomphalaria kuhniana and Biomphalaria amazonica from Colombia. Mem Inst Oswaldo Cruz. 2002:97:997-1004.

37. Dupuy V, Nicot A, Jarne P, David P. Development of 10 microsatellite loci in the pulmonate snail Biomphalaria kuhniana (Mollusca, Gastropoda). Mol Ecol Resour. 2009;9:255-7.

38. Fernandez MA, Pieri OS. Infection by Schistosoma mansoni Sambon 1907 in the first four months of life of Biomphalaria straminea (dunker, 1848) in Brazil. Mem Inst Oswaldo Cruz. 2001:96:185-92.

39. Souza CP, Rodrigues MS, Azevedo ML, Neusa A. Suscetibilidade de populacoes de Biomphalaria straminea (Dunker, 1848) de Minas Gerais, a infeccao por Schistosoma mansoni. Rev Inst Med Trop Säo Paulo. 1981;23: 212-6.

40. Fernandez MA, Thiengo SC. Susceptibility of Biomphalaria straminea (dunker, 1848) from Serra da mesa dam, Goiás, Brazil to infection with three strains of Schistosoma mansoni Sambon, 1907. Mem Inst Oswaldo Cruz. 2002;97:59-60.

41. Qu G, Wang W, Lu X, Dai J, Li X, Liang Y. Evaluating the risk of Schistosoma mansoni transmission in mainland China. Parasitol Res. 2016;115:4711-3. 